\title{
BMJ Open Does adult alcohol consumption combine with adverse childhood experiences to increase involvement in violence in men and women? A cross- sectional study in England and Wales
}

\author{
Mark A Bellis, ${ }^{1,2}$ Karen Hughes, ${ }^{1,2}$ Kat Ford, ${ }^{1}$ Sara Edwards, ${ }^{3}$ Olivia Sharples, ${ }^{4}$ \\ Katie Hardcastle, ${ }^{2}$ Sara Wood ${ }^{2}$
}

To cite: Bellis MA, Hughes $\mathrm{K}$, Ford K, et al. Does adult alcohol consumption combine with adverse childhood experiences to increase involvement in violence in men and women? A cross-sectional study in England and Wales. BMJ Open 2018;8:e020591. doi:10.1136/ bmjopen-2017-020591

- Prepublication history and additional material for this paper are available online. To view these files, please visit the journal online (http://dx.doi org/10.1136/bmjopen-2017020591).

Received 14 November 2017 Revised 10 August 2018 Accepted 4 October 2018

Check for updates

(c) Author(s) (or their employer(s)) 2018. Re-use permitted under CC BY-NC. No commercial re-use. See rights and permissions. Published by BMJ.

${ }^{1}$ College of Health and Behavioural Sciences, Bangor University, Bangor, UK

${ }^{2}$ Policy, Research and International Development Directorate, Public Health Wales, Cardiff, UK

${ }^{3}$ School of Medicine, Trinity College Dublin, Dublin, Republic of Ireland

${ }^{4}$ Exeter Medical School, University of Exeter, Exeter, UK

Correspondence to

Professor Mark A Bellis;

m.a.bellis@bangor.ac.uk

\section{ABSTRACT}

Objectives To examine if, and to what extent, a history of adverse childhood experiences (ACEs) combines with adult alcohol consumption to predict recent violence perpetration and victimisation.

Design Representative face-to-face survey $(n=12669)$ delivered using computer-assisted personal interviewing and self-interviewing.

Setting Domiciles of individuals living in England and Wales.

Participants Individuals aged 18-69 years resident within randomly selected locations. 12669 surveys were completed with participants within our defined age range. Main outcome measures Alcohol consumption was measured using the Alcohol Use Disorders Identification Test-Consumption (AUDIT-C) and childhood adversity using the short ACEs tool. Violence was measured using questions on perpetration and victimisation in the last 12 months.

Results Compliance was $55.7 \%$. There were strong positive relationships between numbers of ACEs and recent violence perpetration and victimisation in both sexes. Recent violence was also strongly related to positive AUDIT-C $(\geq 5)$ scores. In males, heavier drinking and $\geq 4$ ACEs had a strong multiplicative relationship with adjusted prevalence of recent violent perpetration rising from $1.3 \%$ (95\% Cls $0.9 \%$ to $1.9 \%$; 0 ACEs, negative AUDIT-C) to $3.6 \%$ (95\% Cls $2.7 \%$ to $4.9 \%$; 0 ACEs, positive AUDIT-C) and $8.5 \%$ (95\% $\mathrm{Cl} 5.6 \%$ to $12.7 \%$; $\geq 4$ ACEs, negative AUDIT-C) to $28.3 \%$ (95\% Cl $22.5 \%$ to $34.8 \%$; $\geq 4$ ACEs, positive AUDIT-C). In both sexes, violence perpetration and victimisation reduced with age independently of ACE count and AUDIT-C status. The combination of young age (18-29 years), $\geq 4$ ACEs and positive AUDIT-C resulted in the highest adjusted prevalence for both perpetration and victimisation in males $(61.9 \%, 64.9 \%)$ and females $(24.1 \%, 27.2 \%)$.

Conclusions Those suffering multiple adverse experiences in childhood are also more likely to be heavier alcohol users. Especially for males, this combination results in substantially increased risks of violence. Addressing ACEs and heavy drinking together is rarely a feature of public health policy, but a combined approach may help reduce the vast costs associated with both.
Strengths and limitations of this study

- We examined the combined contribution of current alcohol consumption and history of childhood adversity to violence perpetration and victimisation; an area poorly addressed by existing research.

- A large random sample $(n=12669)$ was used from populations across England and Wales.

- Data were collected using established tools to measure exposure to adverse childhood experiences (ACEs) and current alcohol consumption.

- Overall compliance was $55.7 \%$, but it was not possible to identify any selective bias created by refusal to participate.

- Data were self-reported and for ACEs retrospective, and recall bias and reluctance to report could have affected results.

\section{INTRODUCTION}

An increasing number of studies identify the harmful impacts of chronic adversity in childhood (eg, abuse, neglect and exposure to domestic violence) on neurological, hormonal and immunological development. ${ }^{12}$ Exposure to such adverse childhood experiences (ACEs) is associated with subsequent poorer long-term health outcomes. Thus, higher ACEs are linked with greater adoption of health harming behaviours such as substance misuse, along with poor mental health and the earlier development of diseases including diabetes, liver disease and cancer. ${ }^{3-7}$ Exposure to ACEs is also associated with increased involvement in violence in adult life both as a perpetrator and a victim. ${ }^{7}$ Consequently, a propensity for child abuse, domestic violence, sexual violence and self-directed violence in adults have all been linked with a history of ACEs in adult survivors. ${ }^{5-10}$ Intergenerational cycles 
of violence and ACE transmission can occur when individuals who have been exposed to ACEs as a child subsequently expose their own children to violence (eg, child abuse or domestic violence between adults in the household). While the potential evolutionary benefits of developing aggressive tendencies when born into threatening environments have been well elucidated, ${ }^{11}{ }^{12}$ in general the impacts of violence on individual and public health are typically detrimental. Globally, in 2015, interpersonal violence resulted in the loss of 21.4 million disability-adjusted life years. ${ }^{13}$

Exposure to ACEs is also a strong predictor of adolescent and adult problematic alcohol consumption and its consequences (eg, liver disease). ${ }^{4} 71415$ Alcohol misuse in individuals with a history of ACEs can be a coping strategy used to address insecurities and anxieties rooted in a legacy of abuse, neglect and other sources of chronic childhood stress. ${ }^{16}{ }^{17}$ Higher alcohol consumption is also an established catalyst for violence; for instance, around half of all violent acts in England and Wales are thought to be alcohol related. ${ }^{18}$ A meta-analysis of studies from nine countries found an average of $48 \%$ of homicide offenders were reported to be under the influence of alcohol at the time of the offence. ${ }^{19}$ However, only a minority of individuals become violent with alcohol consumption and surprisingly little attention has been given to whether a history of ACEs is a differentiating feature between aggressive and non-aggressive drinkers at a population level.

Neurologically, there are persuasive reasons to suggest alcohol and a history of ACEs are a belligerent mixture. ${ }^{50}$ Exposure to ACEs is associated with functional changes in structures that directly regulate aggressive behaviour (eg, amygdala) ${ }^{21-23}$ Further, chronic childhood stressors lead to poorer development of the prefrontal cortex $(\mathrm{PFC})^{24}$; an area with inhibitory connections to the limbic areas and a key part of the brain's executive functions which help regulate emotional behaviour. Together, amygdala and PFC changes in children exposed to ACEs result, respectively, in a greater propensity for aggressive feelings and poorer executive ability to control them. Because both acute and chronic alcohol intake have been associated with impaired PFC function, ${ }^{22} 24$ the impacts of these chronic changes in brain structure and function are likely to be exacerbated by alcohol consumption across the life course. Such changes are thought to limit individuals' reasoning skills and consequently their ability to view situations from others' perspectives, predict the consequences of one's own actions and diffuse hostile situations. In addition, alcohol-impaired PFC function may limit regulation of aggressive impulses emanating from limbic areas especially in individuals who already have poor anger control as a result of their childhood experiences. Moreover, alcohol may also affect the amygdala directly with intoxication leading to increased reactivity in stressful or threatening situations. ${ }^{25}$

Multiple laboratory studies in both humans and animals have already identified that only a subset of individuals become aggressive after alcohol consumption and such individuals are more likely to have behavioural and neurological features consistent with a propensity for violence. ${ }^{22}$ At a population-level empirical data relating to a history of ACEs, typical drinking behaviour and their combined contribution to involvement in violence are largely absent. Here, we use a series of large national surveys specifically to examine if, and to what extent, a history of ACEs and recent alcohol consumption independently, and in combination, predict perpetration of and victimisation from violence over the past 12 months.

\section{METHODS}

For the purposes of this study, we pool data from four cross-sectional ACE surveys delivered in England and Wales using face-to-face data collection at the home of each respondent.

\section{Study design and instruments}

ACE survey questions $(n=11)$ from the Centers for Disease Control and Prevention short ACE tool were used to measure childhood exposure to abuse and family dysfunction experienced by respondents before 18 years of age (see online supplementary table S1 for full questions). Responses were categorised into nine ACE categories covering: physical, verbal and sexual abuse; parental separation; exposure to domestic violence and growing up in a household with mental illness, alcohol abuse, drug abuse or with an individual who had been incarcerated. As elsewhere, ${ }^{7}$ for the purpose of analysis individuals were categorised according to the number of ACEs they reported $(0,1,2-3$ or $\geq 4 \mathrm{ACE})$. Data on alcohol consumption were collected using the Alcohol Use Disorders Identification Test-Consumption (AUDIT-C) which examines frequency of drinking, quantities consumed on a typical drinking occasion and regularity of binge drinking. ${ }^{26}$ AUDIT-C scores were calculated from responses. A score of $\geq 5$ indicates an individual whose drinking is classified as being at increasing or higher risk (see online supplementary table S1 for full questions and scoring). Consequently, for the purposes of analysis respondents were classified AUDIT-C positive $(\geq 5)$ and negative $(\leq 4)$. Recent involvement in violence (in the last 12 months) was collected by two questions on perpetration and victimisation (online supplementary table S1). Respondents' age and sex were also collected. As the ACE surveys are part of wider studies on life course health, they include additional questions which address other health- related behaviours, longterm health outcomes and health service use but these fields have not been analysed for this study. ${ }^{3427}$

\section{Data collection}

Data were collected through four ACE surveys undertaken across different regions of the UK (Blackburn with Darwen Local Authority (referred to as North England); all of England; South of England; all of Wales; online supplementary table S2). In each case, a random 
stratified sampling approach was used with lower super output areas (LSOAs, small geographical areas with a population mean of 1600) as the sampling unit. Sample selection was stratified first by region (see online supplementary table S2) then within each region by residential deprivation. LSOAs were categorised into quintiles of deprivation based on their ranking in the English and, for Wales, the Welsh Indexes of Multiple Deprivation (IMD) (online supplementary table S2). Each IMD is based on a composite deprivation measure combining data on income, health, employment, education, access to services, community safety and physical environment in order to create a standardised measure for comparing deprivation between small localities. As IMD is measured for small populations occupying a discrete locality, it is routinely used as a measure of socioeconomic status for residents in that locality. ${ }^{28}$ There are some variations in IMD methodologies between studies dependent on year and geography (ie, England and Wales). ${ }^{29} 30$ The national postal code address file was used to identify households of residence in sampled areas and, for English studies, a list of households was randomly selected for inclusion. In Wales, researchers randomly selected households within each sampled area. A variable was included in all multivariate analyses to identify the study membership of each respondent as a potential confounder. For all samples, professional independent data collection teams were employed to undertake the surveys with each team attending at least one ACE training session before data collection began. ${ }^{31-33}$

In the three English studies (online supplementary table S2), selected addresses were sent letters describing the study, identifying when the researchers might visit and providing information on how to opt out. In Wales, letters were presented to potential participants by researchers when they visited selected addresses. All surveys used faceto-face data collection at respondents' places of residence and a combination of CAPI (computer-assisted personal interviewing) and CASI (computer-assisted self-interviewing) for some sensitive questions (eg, those on experiencing ACEs). Paper-based questionnaires were also available for those preferring that medium and surveys were available in multiple languages (including French, Spanish, Polish, Hindi, Punjabi, Urdu, Gujarati, Bengali, Marathi, Pashto, Sindhi, Saraiki, Balochi and Welsh) depending on the ethnic profile of the target population.

Potential participants were given a study information sheet outlining its purpose and the voluntary, confidential and anonymous nature of participation. In all cases, individuals were informed that they were free to withdraw at any point and that withdrawal would not affect any aspects of health treatment or other service provision. Those consenting and meeting the inclusion criteria (within age range, cognitively able to participate in a face-to-face interview and resident in the selected LSOA) completed the questionnaire. Across all four samples, weighted average compliance was $55.7 \%$ (see online supplementary table S2 for response rates for individual samples) giving a total sample size of 13161 . However, the upper age range for Blackburn with Darwen was 70 years (cv. 69 years for all other samples (see online supplementary table S2). In order to ensure that all data in the pooled analyses covered the same age range individuals aged 70 years in the Blackburn with Darwen sample were excluded along with any individuals (in all surveys) who did not complete all questions on ACEs, alcohol or violence. This resulted in a final sample of 12669 (male, $\mathrm{n}=5702$; female $\mathrm{n}=6967$; table 1 ).

\section{Statistical analysis}

Statistical analyses used SPSS V.22. Analyses employed X ${ }^{2}$ and $\mathrm{X}^{2}$ for a trend techniques for initial bivariate analyses and logistic regression modelling to examine the independent relationships between ACEs, alcohol consumption and violence. Adjusted means for recent violence perpetration and victimisation were calculated based on logistic regression models using the estimated marginal means function. ${ }^{34}$ With known differences in levels and characteristics of violence experienced by males and females, ${ }^{18}$ all analyses examined males and females separately. All models included study sample as a variable to account for unrecorded differences between samples.

\section{Patient and public involvement}

The study did not involve patients. Study findings are being made available to participants from the general public via reports and open access journal articles. The participant information sheet provided a web address for participants to access published reports and contact details if they preferred to request publications directly from the research team.

\section{RESULTS}

Nearly twice as many men as women reported being a perpetrator of recent violence and more than twice as many being a victim (table 1 ). Individuals who had perpetrated recent violence were also more likely to report being recent victims (women, $\mathrm{X}^{2}=1629.71, \mathrm{p}<0.001$; men, $\left.X^{2}=2556.15, p<0.001\right)$. In both sexes, there were strong positive relationships between numbers of ACEs experienced and both violence perpetration and victimisation in adulthood (table 1). For example, only $2.8 \%$ of men with no ACEs reported having perpetrated violence in the past year rising to $27.0 \%$ with $\geq 4$ ACEs. Equally, in both sexes AUDIT-C positive scores were significantly associated with higher recent violence perpetration and victimisation. Perpetration and victimisation decreased consistently (for men and women) with age and increased with increasing deprivation; although the relationship between deprivation and violence perpetration in women barely reached significance (table 1). Only violence in males showed any significant relationship with ethnicity, with Asian ethnicity associated with lower levels of victimisation. Further, while study sample had no relationship with violence in women and region 
Table 1 Relationships between levels of violence perpetration and victimisation in the last 12 months and ACE count, AUDIT-C and demographic variables

\begin{tabular}{|c|c|c|c|c|c|c|c|c|c|}
\hline \multirow[b]{3}{*}{ Variable } & \multirow[b]{3}{*}{ Category } & \multicolumn{8}{|c|}{ Involvement in violence in last 12 months } \\
\hline & & \multicolumn{4}{|c|}{ Male (\% positive) } & \multicolumn{4}{|c|}{ Female (\% positive) } \\
\hline & & $\mathbf{n}$ & $\% *$ & Perpetrator & Victim & $\mathbf{n}$ & $\% *$ & Perpetrator & Victim \\
\hline All & & 5702 & 100.0 & 6.4 & 7.6 & 6967 & 100.0 & 3.3 & 3.5 \\
\hline \multirow[t]{6}{*}{ ACE count } & 0 & 3180 & 55.8 & 2.8 & 3.8 & 3893 & 55.9 & 1.3 & 1.2 \\
\hline & 1 & 1149 & 20.2 & 4.9 & 6.4 & 1369 & 19.6 & 2.1 & 2.2 \\
\hline & $2-3$ & 885 & 15.5 & 9.9 & 10.4 & 1023 & 14.7 & 6.3 & 7.4 \\
\hline & $\geq 4$ & 488 & 8.6 & 27.0 & 29.5 & 682 & 9.8 & 13.0 & 13.3 \\
\hline & $\mathrm{X}_{\text {trend }}^{2}$ & & & 350.203 & 320.528 & & & 286.685 & 309.737 \\
\hline & $P$ values & & & $<0.001$ & $<0.001$ & & & $<0.001$ & $<0.001$ \\
\hline AUDIT-C & $\leq 4$ & 3584 & 62.9 & 3.4 & 4.2 & 5598 & 80.4 & 2.6 & 2.7 \\
\hline \multirow[t]{3}{*}{ Score } & $\geq 5$ & 2118 & 37.1 & 11.6 & 13.2 & 1369 & 19.6 & 6.4 & 6.9 \\
\hline & $x^{2}$ & & & 148.710 & 151.993 & & & 49.098 & 57.055 \\
\hline & $P$ & & & $<0.001$ & $<0.001$ & & & $<0.001$ & $<0.001$ \\
\hline \multirow[t]{7}{*}{ Age group } & $18-29$ & 1390 & 24.4 & 15.8 & 18.1 & 1491 & 21.4 & 5.7 & 6.8 \\
\hline & $30-39$ & 1022 & 17.9 & 6.8 & 7.8 & 1546 & 22.2 & 3.9 & 4.0 \\
\hline & $40-49$ & 1098 & 19.3 & 3.6 & 5.3 & 1465 & 21.0 & 3.6 & 3.3 \\
\hline & $50-59$ & 1009 & 17.7 & 2.5 & 2.7 & 1155 & 16.6 & 1.5 & 2.2 \\
\hline & $60-69$ & 1183 & 20.7 & 0.9 & 0.3 & 1310 & 18.8 & 1.1 & 0.5 \\
\hline & $x^{2}$ & & & 304.668 & 328.948 & & & 60.295 & 92.508 \\
\hline & $P$ values & & & $<0.001$ & $<0.001$ & & & $<0.001$ & $<0.001$ \\
\hline \multirow[t]{7}{*}{ Deprivation } & 1 (least) & 1312 & 23.0 & 5.1 & 6.3 & 1516 & 21.8 & 2.6 & 2.2 \\
\hline & 2 & 1072 & 18.8 & 6.3 & 6.8 & 1308 & 18.8 & 3.3 & 3.7 \\
\hline & 3 & 1090 & 19.1 & 5.5 & 7.3 & 1304 & 18.7 & 3.1 & 3.1 \\
\hline & 4 & 1061 & 18.6 & 6.6 & 7.8 & 1366 & 19.6 & 3.8 & 3.9 \\
\hline & 5 (most) & 1167 & 20.5 & 8.7 & 9.6 & 1473 & 21.1 & 3.8 & 4.7 \\
\hline & $\mathrm{X}_{\text {trend }}^{2}$ & & & 11.036 & 9.794 & & & 4.114 & 11.984 \\
\hline & & & & $<0.001$ & 0.002 & & & 0.043 & $<0.001$ \\
\hline \multirow[t]{5}{*}{ Ethnicity } & White & 4723 & 82.8 & 6.7 & 8.1 & 5873 & 84.3 & 4.9 & 3.6 \\
\hline & Asian & 685 & 12.0 & 4.7 & 4.1 & 748 & 10.7 & 3.6 & 2.4 \\
\hline & Other & 294 & 5.2 & 5.4 & 7.1 & 346 & 5.0 & 4.5 & 4.6 \\
\hline & $x^{2}$ & & & 4.725 & 13.779 & & & 1.711 & 4.040 \\
\hline & $P$ values & & & 0.094 & 0.001 & & & 0.425 & 0.133 \\
\hline Study & England & 1734 & 30.4 & 5.7 & 6.9 & 2122 & 30.5 & 3.3 & 3.8 \\
\hline \multirow[t]{5}{*}{ Sample† } & Wales & 991 & 17.4 & 11.7 & 13.9 & 1006 & 14.4 & 4.1 & 4.6 \\
\hline & South England & 2427 & 42.6 & 4.2 & 4.7 & 2999 & 43.0 & 2.9 & 3.0 \\
\hline & North England & 550 & 9.7 & 9.1 & 10.9 & 840 & 12.1 & 3.8 & 3.3 \\
\hline & $x^{2}$ & & & 74.187 & 96.601 & & & 3.814 & 6.640 \\
\hline & $\mathrm{P}$ & & & $<0.001$ & $<0.001$ & & & 0.282 & 0.084 \\
\hline
\end{tabular}

${ }^{*}$ Percentage of total sample within each category.

†See online supplementary table S2 for more details.

ACE, adverse childhood experiences; AUDIT-C, Alcohol Use Disorders Identification Test-Consumption.

of residence, levels of perpetration and victimisation for males were higher in the Welsh and North England samples. In both sexes, increasing ACE count was significantly related to higher prevalence of AUDIT-C positive (ACE categories $0,1,2-3, \geq 4$, respectively: AUDIT-C positive; males, $31.6 \%, 42.8 \%, 41.4 \%, 53.2 \%$, $\chi^{2}=112.107, \mathrm{p}<0.001 ;$ females, $15.7 \%, 22.8 \%, 22.3 \%$, $\left.32.1 \%, \chi^{2}=118.314, \mathrm{p}<0.001\right)$. 
Table 2 examines the independent contributions of AUDIT-C and ACE count variables to violence perpetration and victimisation. In both sexes, ACE count and AUDIT-C status remained strongly related to violence, with significantly higher levels of violence perpetration and victimisation with AUDIT-C positive scores and at all ACE counts (vs 0 ACEs); except for perpetration of violence in females with one ACE. Age was also independently associated with both perpetration and victimisation with decreasing involvement in each as age increased. After correcting for ACEs and AUDIT-C, there were no significant effects from ethnicity or deprivation on violence perpetration or victimisation (table 2). As with bivariate analyses (table 1), study location remained a predictive factor for perpetration and victimisation in men but not in women (table 2). Interactions between ACE count and AUDIT-C status as well as for each with age were also included in the model. For men only interactions between ACE count and AUDIT-C significantly contributed to violence perpetration and victimisation models; no interactions with age were significant.

Logistic regression models were used to calculate adjusted means (adjusted to overall sample characteristics) for violence perpetration and victimisation by ACE count and AUDIT-C status (figure 1A,B; unadjusted means of perpetration and victimisation rates are presented in online supplementary table S3). For both sexes, violence perpetration and victimisation were higher in all ACE count categories when combined with a positive AUDIT-C with greatest increases seen for perpetration in those with $\geq 4$ ACEs. Thus, for males, prevalence of perpetration in those with $\geq 4$ ACEs and AUDIT-C positive was over three times the levels in those with $\geq 4$ ACEs but AUDIT-C negative (figure 1A). For women, perpetration was also higher with a positive AUDIT-C (figure 1A). However, while this difference was again greatest in the $\geq 4$ ACEs category, the increase in violence perpetration with AUDIT-C positive was not as marked as with men.

With age also contributing significantly to the model (table 2), adjusted means were calculated for each age group (figure 2A,B). Recent violence perpetration by males in those aged 18-29 years reduced from a peak of $61.9 \%$ where there was both a positive AUDIT-C and $\geq 4$ ACEs to only $5.3 \%$ in the same age group for those with no ACEs and a negative AUDIT-C. Female respondents (aged 18-29 years) showed a similar, although less marked, reduction from $24.1 \%$ to $1.8 \%$, respectively (figure $2 \mathrm{~A}$ ). Recent victimisation followed a similar pattern with, for instance, prevalence in women aged 18-29 years falling from $27.2 \%$ in those with a positive AUDIT-C and $\geq 4$ ACEs to only $2.1 \%$ in those with no ACEs and a negative AUDIT-C (figure 2B). For both sexes and both perpetration and victimisation, prevalence reduced with age in all ACE count and AUDIT-C combinations (figure 2; table 2). However, even at ages $\geq 50$ years in both sexes modelled estimates suggest higher risks of perpetration and victimisation in those AUDIT-C positive with $\geq 4$ ACEs. While in those with $\geq 4$ ACEs across all age groups, a negative AUDIT-C was associated with a reduced risk of perpetration and victimisation in men (vs AUDIT-C positive and $\geq 4$ ACEs), this was less marked in women.

\section{DISCUSSION}

Consistent with studies elsewhere ${ }^{7} 223536$ this study showed that both higher alcohol consumption and increased ACEs independently contribute to greater involvement in violence for both sexes as both perpetrators and victims (table 2). Critically, however, when high ACE counts and higher alcohol consumption occur in males, there appears to be a substantive multiplicative increase in risks of violence (figure 1). Thus, in men, prevalence of violence perpetration was $3.6 \%$ in those with an AUDIT-C positive only and $8.5 \%$ in those with $\geq 4$ ACEs count only (including the baseline risk of $1.3 \%$ with neither condition). By comparison, when both conditions were present, violence perpetration prevalence was 28.3\%; 2.3 times higher than the combined individual risks (figure 1A). These findings are consistent with a proportion of drinkers being particularly susceptible to developing violent tendencies when drinking alcohol. ${ }^{20} 37$ Results here suggest that such susceptibility to alcohol-related violence, especially in men, may be based in childhoods affected by multiple types of adversity.

The Crime Survey for England and Wales estimates that, in those aged $\geq 16$ years, 1.3 million violent incidents occurred in 2015/2016 of which $40 \%$ were alcohol related. ${ }^{18}$ While results here cannot identify how many such incidents are related to combined ACEs and heavy adult drinking, this may account for a substantive proportion. Heavy drinking with high ACEs is relatively common as individuals with more ACEs are also more likely to be heavier drinkers; a finding consistent with studies elsewhere. ${ }^{638}$ Thus, $8.6 \%$ of males here reported $\geq 4$ ACEs (cv. other countries, eg, USA, $15 \%{ }^{39}$; Philippines, $10 \%{ }^{40}$ ) with over half (53.2\%) AUDIT-C positive; resulting in nearly 1 in 20 males with a $\geq 4$ ACE-AUDIT-C positive combination. This subpopulation has an estimated violence perpetration prevalence 21 times higher than males with no ACEs and AUDIT-C negative (figure 1A) and victimisation rate 17 times higher (figure 1B).

For women, there are multiple well-established genetic and cultural factors contributing to lower levels of violence perpetration than in men. ${ }^{41}{ }^{42}$ Here, although women suffered similar ACE counts to men, recent violence perpetration was lower across all ACE counts (table 1, figure 1A). Further, while there was an additive impact of ACEs and AUDIT-C status in women, there was no substantive multiplicative effect in those with $\geq 4$ ACEs. Our data cannot identify mechanisms that might underlie differences in sexes. However, how much violence results from alcohol reducing impulse control should depend on the strength of violent impulses otherwise suppressed through the PFC control. Our results would suggest a more extensive underlying propensity for violence in males with $\geq 4$ ACEs, a greater impact of heavier alcohol 


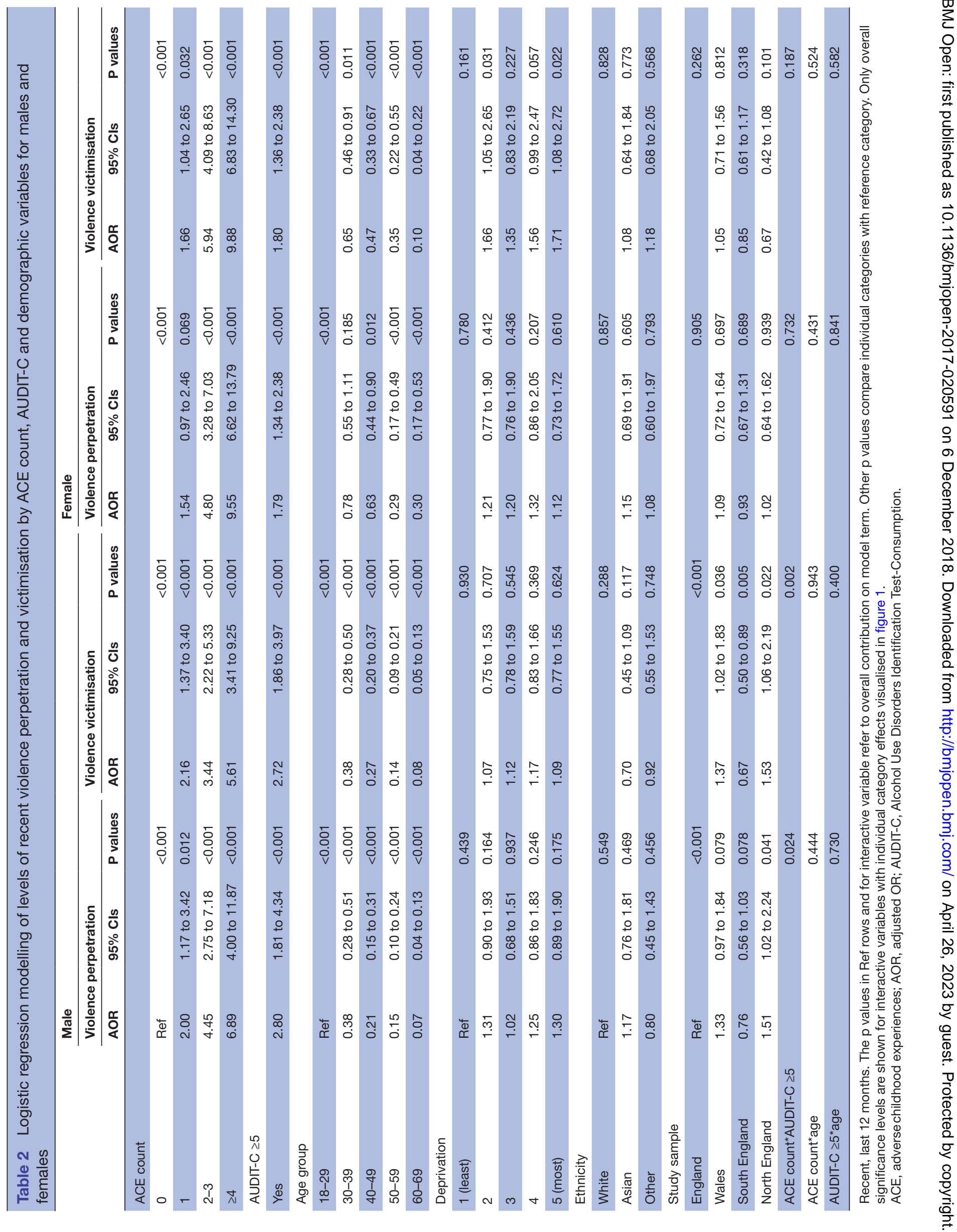


A Violence perpetration

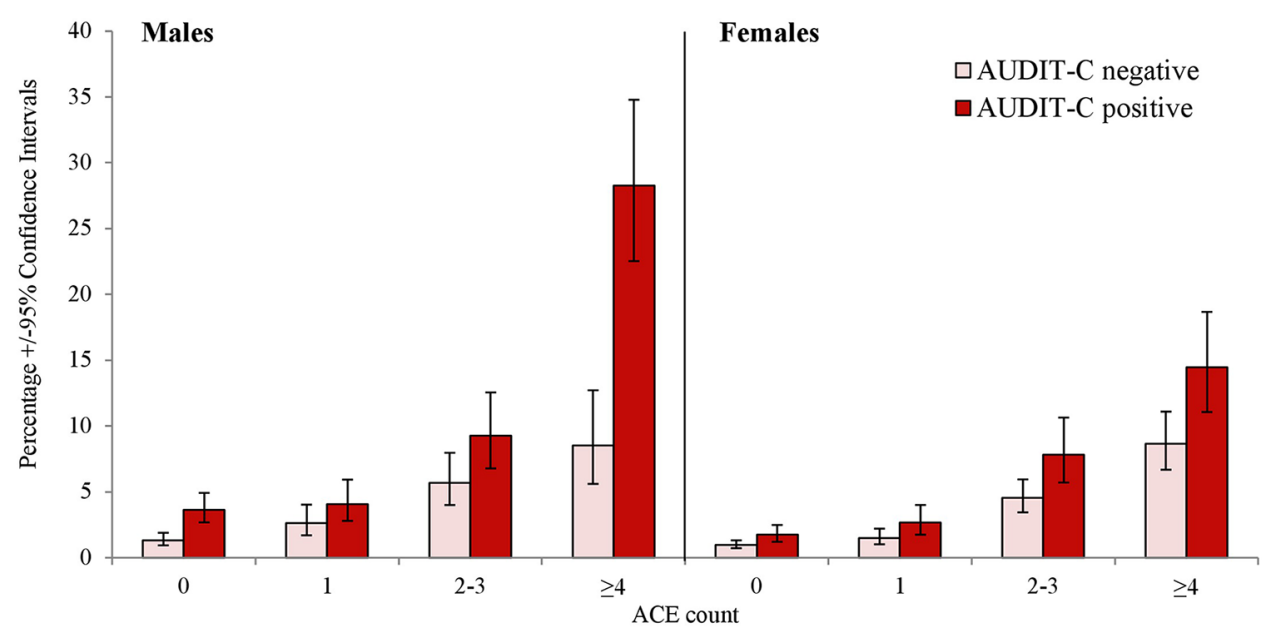

B Violence victimisation

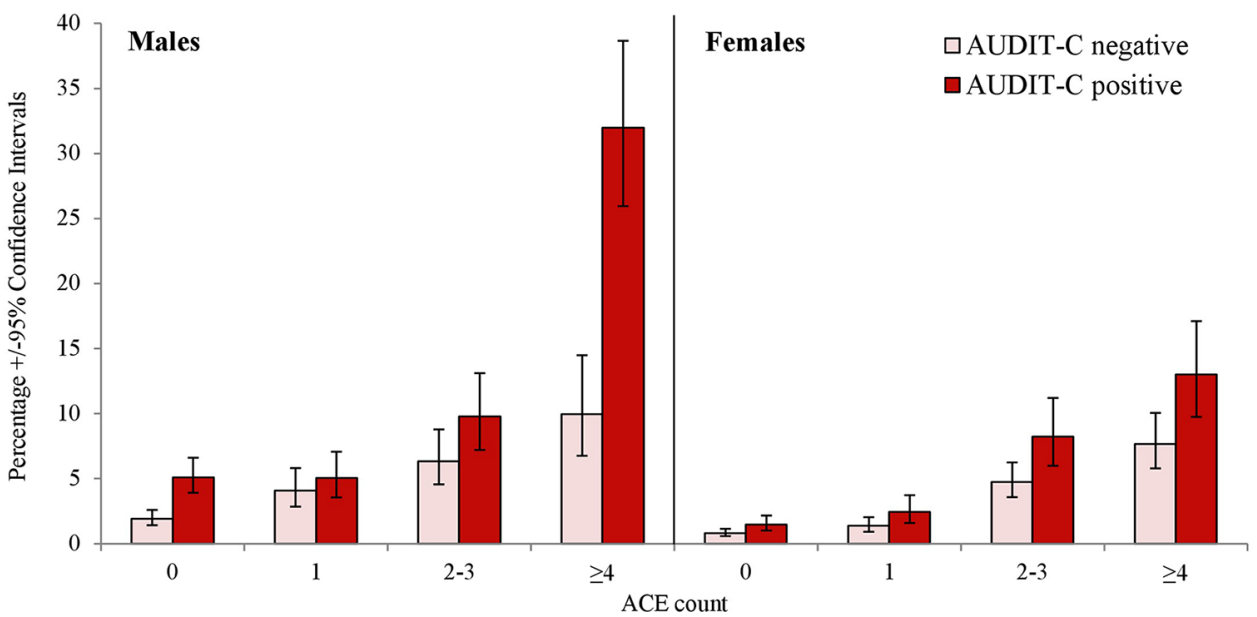

Figure 1 Adjusted mean percentage of individuals involved in recent ${ }^{a}$ violence within each ACE count category stratified by AUDIT-C status (A) violence perpetration (B) violence victimisation. Adjusted means are calculated using an estimated marginal mean methodology (see Methods section). AUDIT-C positive indicates a score of $\geq 5$ and negative $\leq 4$. ${ }^{a}$ Recent=in last 12 months. ACE, adverse childhood experiences; AUDIT-C, Alcohol Use Disorders Identification Test-Consumption.

consumption on PFC control or a combination of both. Further, women typically have a greater tendency to self-directed violence (eg, self-harm) and such behaviour, while related elsewhere with alcohol ${ }^{43}$ and ACEs, ${ }^{7}$ was not measured here.

The impacts of $\geq 4$ ACEs and heavier alcohol consumption on violence appear to persist across age groups for both sexes (table 2; figure 2). Other studies have shown higher levels of violence in males and younger age groups. ${ }^{44}$ Here, due to the interaction between ACEs and alcohol consumption, violence perpetration was the norm $(61.9 \%)$ for males aged $18-29$ years with $\geq 4$ ACEs and AUDIT-C positive. It was also frequent $(24.1 \%)$ for equivalent females (figure 2A). For both sexes, there were similar relationships between ACE-AUDIT-C interactions and both violence perpetration and victimisation (figure 1). Strong correlations between individuals experiencing violence perpetration and victimisation have also been reported elsewhere. Thus, a systematic review (covering literature between 1958 and 2011) found consistent support for a substantive overlap between those individuals who report being offenders and those who report being victims of violence. ${ }^{45}$ Poor quality childhoods (eg, including abuse and neglect) can leave individuals with limited skills to negotiate out of threatening situations, increased fearlessness and a diminished ability to consider the consequences of one's actions; all of which can make both victimisation and perpetration more likely. ${ }^{7}$ The addition of alcohol is likely to further impair individuals' abilities to consider the potential repercussions, of or to avoid involvement in, violence. Moreover, a history of ACEs can leave individuals seeing violence as an acceptable resolution to their own or others' problems. ${ }^{46}$ Consequently, ACE affected individuals may remain in violently abusive relationships with alcohol consumption used as a coping mechanism as well as alcohol potentially 
A violence perpetration

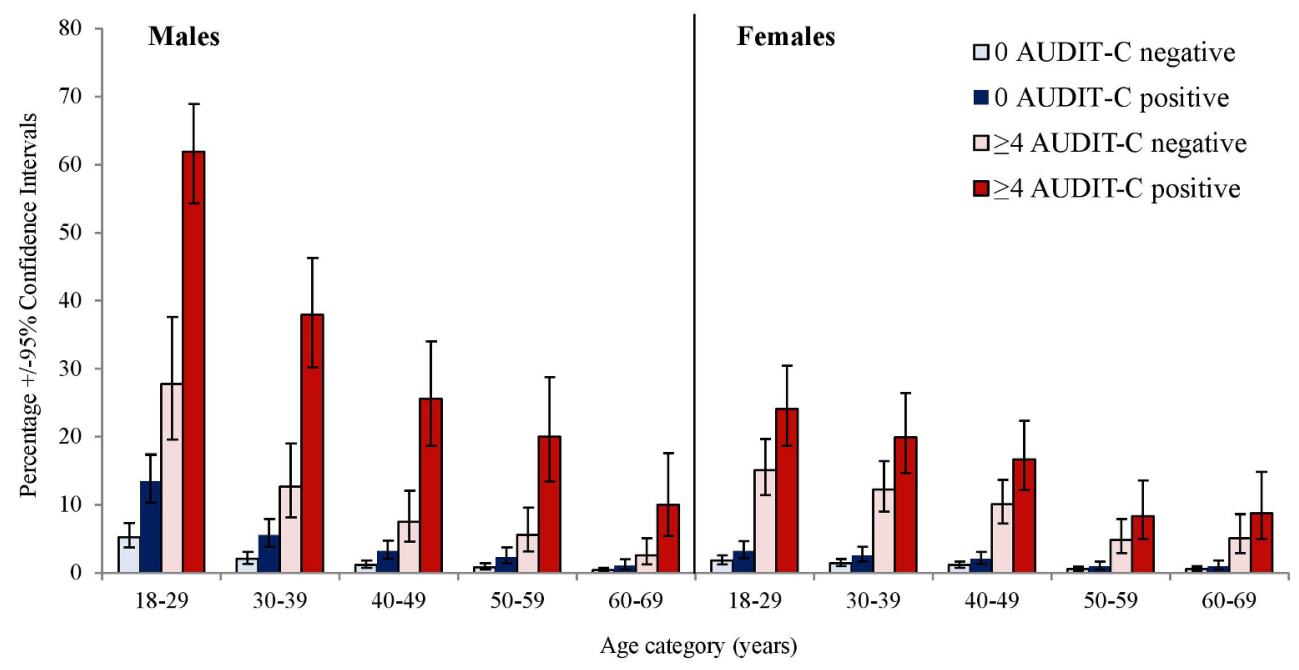

B Violence victimisation

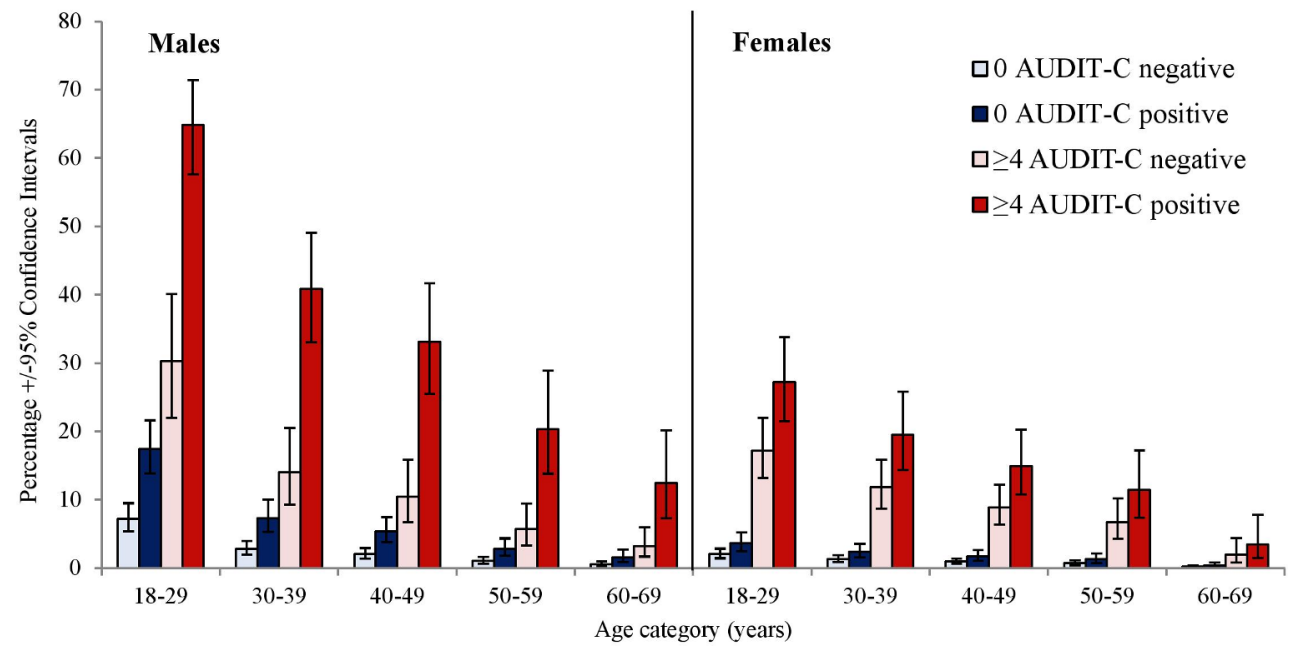

Figure 2 Adjusted mean percentage of individuals involved in recent ${ }^{a}$ violence with no and $\geq 4$ ACEs within age groups, stratified by AUDIT-C status (A) violence perpetration (B) violence victimisation. Adjusted means are calculated using an estimated marginal mean methodology (see Methods section). AUDIT-C positive indicates a score of $\geq 5$ and negative $\leq 4$. ${ }^{a}$ Recent=in last 12 months. ACE, adverse childhood experiences; AUDIT-C, Alcohol Use Disorders Identification TestConsumption.

acting as an additional aggravating factor. ${ }^{47} 48$ Results here are consistent with an additive impact of ACEs and alcohol on risks of victimisation; although for males, risks appear again to be multiplied when high ACE counts and heavier drinking co-occur (figure 2). Finally, while for both victimisation and perpetration there were positive relationships between violence and deprivation (table 1) these disappeared once alcohol consumption and ACE count were taken into account. Findings suggest alcohol and childhood trauma are likely to be major components in the association between deprivation and violence as reported in multiple countries. ${ }^{49-51}$

This study has some important limitations. The samples were demographically representative of the populations being studied ${ }^{32}$ but overall compliance was only $55.7 \%$. However, it is not possible to identify or exclude any selective bias created by refusal to participate. Data were self-reported and in the case of ACEs retrospective. Recall bias and any reluctance to report certain current behaviours or historical experiences could also have affected results. Our data suggest multiplicative effects on risk of violence when multiple ACEs and heavier alcohol use are combined in men. However, analyses presented here are based on retrospective and cross-sectional data and alone cannot establish causality. Longitudinal studies are required to sequentially examine the independent and combined impacts of childhood adversity and adult alcohol consumption on involvement in violence. Moreover, laboratory work is needed to understand any mechanisms underpinning such relationships including the potential role of hormonal and other differences between sexes that have previously been linked with aggression. ${ }^{4152}$ Our measures of violence were also limited to single questions on perpetration and victimisation as 
well as to behaviour in the last 12 months. Research is required to examine relationships between ACEs, alcohol and severity of violence or types of violence (eg, public or domestic settings). Such distinctions are considerations for future studies in order to describe how violence resulting from ACEs in one generation may contribute to increased violence against women and children and consequently higher ACEs in subsequent generations.

\section{CONCLUSIONS}

Violence is an international economic and public health challenge resulting in over half a million deaths and costing an estimated \$14 trillion per year globally. ${ }^{53}$ A large proportion of violent deaths ${ }^{19}$ and non-fatal violence ${ }^{36}$ is alcohol related. Results here are consistent with heavier alcohol consumption, especially in males, eroding executive control over violent tendencies established by exposure to multiple ACEs and consequently contributing to substantially increased engagement in adult violence. Interventions to restrict alcohol consumption in those with a history of violence are already in use.$^{55}$ However, examining the ACE exposure of patients and offenders may help better identify those who will benefit from programmes as well as those who use alcohol as part of an ACE coping strategy. Thus, addressing the legacy of ACEs in such violent individuals may help control aggression and reduce the need for heavy drinking. For most legal drugs, their sale is dependent on informing users about their potential adverse reactions and the types of conditions that make individuals susceptible to them. A greater public awareness of the relationships between ACEs, alcohol and violence may help individuals manage their own risks of violence as well as risks relating to those around them. For over two thousand years, established wisdoms such as in vino veritas (in wine truth) suggest that alcohol exposes underlying traits which people otherwise attempt to suppress. Results here support such wisdom and provide epidemiological evidence that violent impulses established in childhood can be exposed by alcohol consumption.

Acknowledgements We are very grateful to the residents of England and Wales who kindly participated in the surveys and to the staff of BMG research and Future Focus Research for data collection. We would also like to thank Caoimhe Martin, Alisha Davies, Kathryn Ashton, Nicola Leckenby, Nadia Butler, Zara Quigg, Helen Lowey, Dominic Harrison, Ann Robins, Peter Barker, David Conrad, Kelly 0'Neill, Chandraa Bhattacharya and Barbara Paterson for their support with the development and delivery of the research.

Contributors MAB and KHu designed and directed the studies. MAB undertook the analyses and wrote the first draft of this manuscript. KHu and KF coordinated study implementation, contributed to data management and edited the manuscript. $\mathrm{KHa}$ contributed to data management and manuscript editing. SE, OS and SW contributed to literature review, data quality assurance and manuscript editing.

Funding The studies were funded by Public Health Wales; Public Health England; Luton, Northamptonshire and Hertfordshire Councils; Higher Education Funding Council for England; and National Health Service Research and Development Funds.

Competing interests None declared.

Patient consent Not required.
Ethics approval Ethical approval for all studies was obtained through Liverpool John Moores University Research Ethics Panel with additional approval provided by Public Health Wales for the Welsh survey.

Provenance and peer review Not commissioned; externally peer reviewed.

Data sharing statement The datasets analysed in the current study are available from the corresponding author on reasonable request.

Open access This is an open access article distributed in accordance with the Creative Commons Attribution Non Commercial (CC BY-NC 4.0) license, which permits others to distribute, remix, adapt, build upon this work non-commercially, and license their derivative works on different terms, provided the original work is properly cited, appropriate credit is given, any changes made indicated, and the use is non-commercial. See: http://creativecommons.org/licenses/by-nc/4.0/.

\section{REFERENCES}

1. Danese A, McEwen BS. Adverse childhood experiences, allostasis, allostatic load, and age-related disease. Physiol Behav 2012;106:29-39.

2. Teicher $\mathrm{MH}$, Samson JA. Annual research review: enduring neurobiological effects of childhood abuse and neglect. J Child Psychol Psychiatry 2016;57:241-66.

3. Bellis MA, Hughes K, Leckenby N, et al. National household survey of adverse childhood experiences and their relationship with resilience to health-harming behaviors in England. BMC Med 2014;12:1-10.

4. Bellis MA, Hughes $\mathrm{K}$, Leckenby $\mathrm{N}$, et al. Measuring mortality and the burden of adult disease associated with adverse childhood experiences in England: a national survey. J Public Health 2015;37:445-54.

5. Anda RF, Felitti VJ, Bremner JD, et al. The enduring effects of abuse and related adverse experiences in childhood. A convergence of evidence from neurobiology and epidemiology. Eur Arch Psychiatry Clin Neurosci 2006;256:174-86.

6. Campbell JA, Walker RJ, Egede LE. Associations between adverse childhood experiences, high-risk behaviors, and morbidity in adulthood. Am J Prev Med 2016;50:344-52.

7. Hughes K, Bellis MA, Hardcastle KA, et al. The effect of multiple adverse childhood experiences on health: a systematic review and meta-analysis. Lancet Public Health 2017;2:e356-e366.

8. Bellis MA, Hughes K, Leckenby N, et al. Adverse childhood experiences and associations with health-harming behaviours in young adults: surveys in eight eastern European countries. Bull World Health Organ 2014;92:641-55.

9. Ports KA, Ford DC, Merrick MT. Adverse childhood experiences and sexual victimization in adulthood. Child Abuse Negl 2016;51:313-22.

10. Randell KA, O'Malley D, Dowd MD. Association of parental adverse childhood experiences and current child adversity. JAMA Pediatr 2015;169:786-7.

11. Del Giudice M, Ellis BJ. Evolutionary foundations of developmental psychopathology. Cicchetti D, Developmental Psychopathology, Vol. 2: Developmental Neuroscience (3rd edition). New York: Wiley \& Sons, 2016:1-58.

12. Bjorklund DF, Hawley PH. Aggression grows up: looking through an evolutionary developmental lens to understand the causes and consequences of human aggression. In: Shackelford TK, Hansen $\mathrm{RD}$, eds. The evolution of violence. New York: Springer-Verlag, 2014:159-86.

13. GBD 2015 DALYs and HALE Collaborators. Global, regional, and national disability-adjusted life-years (DALYs) for 315 diseases and injuries and healthy life expectancy (HALE), 1990-2015: a systematic analysis for the Global Burden of Disease Study 2015. Lancet 2016;388:1603-58.

14. Dong M, Dube SR, Felitti VJ, et al. Adverse childhood experiences and self-reported liver disease: new insights into the causal pathway. Arch Intern Med 2003;163:1949-56.

15. Dube SR, Miller JW, Brown DW, et al. Adverse childhood experiences and the association with ever using alcohol and initiating alcohol use during adolescence. J Adolesc Health 2006;38:444.e1-444.e10.

16. Strine TW, Dube SR, Edwards VJ, et al. Associations between adverse childhood experiences, psychological distress, and adult alcohol problems. Am J Health Behav 2012;36:408-23.

17. Rothman EF, Edwards EM, Heeren T, et al. Adverse childhood experiences predict earlier age of drinking onset: results from a representative US sample of current or former drinkers. Pediatrics 2008;122:e298-e304.

18. Wright E. Focus on violent crime and sexual offences, England and Wales: year ending mar 2016. 2017 https://www.ons.gov.uk/peop lepopulationandcommunity/crimeandjustice/compendium/focusonv 
iolentcrimeandsexualoffences/yearendingmarch2016 (accessed 11 Jul 2017).

19. Kuhns JB, Exum ML, Clodfelter TA, et al. The prevalence of alcoholinvolved homicide offending: a meta-analytic review. Homicide Stud 2014;18:251-70.

20. Giancola PR. Executive functioning: a conceptual framework for alcohol-related aggression. Exp Clin Psychopharmacol 2000;8:576-97.

21. Lane SD, Kjome KL, Moeller FG. Neuropsychiatry of aggression. Neurol Clin 2011;29:49-64.

22. Heinz AJ, Beck A, Meyer-Lindenberg A, et al. Cognitive and neurobiological mechanisms of alcohol-related aggression. Nat Rev Neurosci 2011;12:400-13.

23. Pechtel P, Pizzagalli DA. Effects of early life stress on cognitive and affective function: an integrated review of human literature. Psychopharmacology 2011;214:55-70.

24. Abernathy K, Chandler LJ, Woodward JJ. Alcohol and the prefrontal cortex. Int Rev Neurobiol 2010;91:289-320.

25. Gan G, Sterzer P, Marxen M, et al. Neural and behavioral correlates of alcohol-induced aggression under provocation. Neuropsychopharmacology 2015;40:2886-96.

26. Bush K, Kivlahan DR, McDonell MB, et al. The AUDIT alcohol consumption questions (AUDIT-C): an effective brief screening test for problem drinking. Arch Intern Med 1998;158:1789-95.

27. Bellis MA, Hughes $\mathrm{K}$, Hardcastle $\mathrm{K}$, et al. Measuring the impact of adverse childhood experiences on health service use across the life course using a retrospective cohort study. J Health Serv Res Policy 2017;22:168-77.

28. Department for Communities and Local Government. The English Indices of Deprivation 2015 - frequently asked questions. https:// assets.publishing.service.gov.uk/government/uploads/system/ uploads/attachment_data/file/579151/English_Indices_of Deprivation_2015_-_Frequently_Asked_Questions_Dec_2016.pdf (Accessed 9 May 2018).

29. Public Health England. Adjusted IMD 2010 scores for 2011 LSOAs. 2010 http://webarchive.nationalarchives.gov.uk/20160926225835/ http://www.apho.org.uk/resource/item.aspx?RID=125887

30. Office of National Statistics. Welsh Index of Multiple Deprivation. http://gov.wales/statistics-and-research/welsh-index-multipledeprivation/?lang=en (Accessed 1 Dec 2015).

31. Bellis MA, Lowey H, Leckenby N, et al. Adverse childhood experiences: retrospective study to determine their impact on adult health behaviours and health outcomes in a UK population. $J$ Public Health 2014;36:81-91.

32. Ford K, Butler N, Hughes K, et al. Adverse childhood experiences in Hertfordshire, Luton and Northamptonshire. Liverpool: Centre for Public Health, 2016.

33. Bellis MA, Ashton K, Hughes K, et al. Adverse childhood experiences and their impact on health-harming behaviours in the Welsh population. Cardiff: Public Health Wales, 2015.

34. IBM. IBM SPSS advanced statistics 22. Armonk, NY: IBM Corporation, 2013.

35. Duke NN, Pettingell SL, McMorris BJ, et al. Adolescent violence perpetration: associations with multiple types of adverse childhood experiences. Pediatrics 2010;125:e778-e786.

36. Cherpitel $\mathrm{CJ}, \mathrm{Ye} \mathrm{Y}$, Bond J, et al. Alcohol attributable fraction for injury morbidity from the dose-response relationship of acute alcohol consumption: emergency department data from 18 Countries. Addiction 2015;110:1724-32.
37. Parrott DJ, Giancola PR. A further examination of the relation between trait anger and alcohol-related aggression: the role of anger control. Alcohol Clin Exp Res 2004;28:855-64.

38. Xiao Q, Dong MX, Yao J, et al. Parental alcoholism, adverse childhood experiences, and later risk of personal alcohol abuse among Chinese medical students. Biomed Environ Sci 2008;21:411-9.

39. Metzler M, Merrick MT, Klevens J, et al. Adverse childhood experiences and life opportunities: shifting the narrative. Child Youth Serv Rev 2017;72:141-9.

40. Ramiro LS, Madrid BJ, Brown DW. Adverse childhood experiences (ACE) and health-risk behaviors among adults in a developing country setting. Child Abuse Negl 2010;34:842-55.

41. Staniloiu A, Markowitsch H. Gender differences in violence and aggression - a neurobiological perspective. Procedia Soc Behav Sci 2012;33:1032-6.

42. Niehoff $D$. Not Hardwired: the complex neurobiology of sex differences in violence. Violence Gend 2014;1:19-24.

43. Ness J, Hawton K, Bergen $\mathrm{H}$, et al. Alcohol use and misuse, selfharm and subsequent mortality: an epidemiological and longitudinal study from the multicentre study of self-harm in England. Emerg Med $J$ 2015;32:793-9.

44. Krug EG, Mercy JA, Dahlberg LL, et al. The world report on violence and health. Geneva: World Health Organization, 2002.

45. Jennings WG, Piquero AR, Reingle JM. On the overlap between victimization and offending: A review of the literature. Aggress Violent Behav 2012;17:16-26.

46. Widom CS, Wilson HW. Intergenerational transmission of violence. In: Lindert J, Levav I, eds. Violence and mental health. Netherlands: Springer, 2015:27-45.

47. Devries KM, Child JC, Bacchus LJ, et al. Intimate partner violence victimization and alcohol consumption in women: a systematic review and meta-analysis. Addiction 2014;109:379-91.

48. Graham K, Bernards S, Wilsnack SC, et al. Alcohol may not cause partner violence but it seems to make it worse: a cross national comparison of the relationship between alcohol and severity of partner violence. J Interpers Violence 2011;26:1503-23.

49. Bellis MA, Hughes K, Wood S, et al. National five-year examination of inequalities and trends in emergency hospital admission for violence across England. Inj Prev 2011;17:319-25.

50. Lachaud J, Donnelly PD, Henry D, et al. A population-based study of homicide deaths in Ontario, Canada using linked death records. Int $J$ Equity Health 2017;16:133.

51. Sabina C. Individual and national level associations between economic deprivation and partner violence among college students in 31 national settings. Aggress Behav 2013;39:247-56.

52. Batrinos ML. Testosterone and aggressive behavior in man. Int $J$ Endocrinol Metab 2012;10:563-8.

53. GBD 2015 Mortality and Causes of Death Collaborators. Global, regional, and national life expectancy, all-cause mortality, and causespecific mortality for 249 causes of death, 1980-2015: a systematic analysis for the global burden of disease study 2015. Lancet 2016;388:1459-544.

54. The Institute for Economics and Peace. The economic value of peace 2016: measuring the global economic impact of violence and conflict Sydney: Institute for Economics and Peace, 2016.

55. Shaw D, McCluskey K, Linden W, et al. Reducing the harmful effects of alcohol misuse: the ethics of sobriety testing in criminal justice. $J$ Med Ethics 2012;38:669-71. 